Article

\title{
Immunogenicity and Cross-Protective Efficacy Induced by Outer Membrane Proteins from Salmonella Typhimurium Mutants with Truncated LPS in Mice
}

\author{
Qiong Liu ${ }^{1, \dagger}{ }^{\dagger}$, Qing Liu ${ }^{2, *},{ }^{+}$, Xinxin Zhao ${ }^{1}$, Tian Liu ${ }^{1}$, Jie $\mathrm{Yi}^{1}{ }^{1}$, Kang Liang ${ }^{1}$ and Qingke Kong ${ }^{1, *}$ \\ 1 Institute of Preventive Veterinary Medicine, Sichuan Agricultural University, Chengdu 611130, China; \\ p19890528@126.com (Q.L.); xxinzhao@163.com (X.Z.); 1t9208101223@163.com (T.L.); jelly187@163.com (J.Y.); \\ LKang024@163.com (K.L.) \\ 2 Department of Bioengineering, College of Veterinary Medicine, Sichuan Agricultural University, \\ Chengdu 611130, China \\ * Correspondence: qing.liu.2@sicau.edu.cn (Q.L.); kongqiki@163.com (Q.K.); \\ Tel.: +86-28-8629-1176 (Q.L. \& Q.K.) \\ + These authors contributed equally to this work. \\ Academic Editor: Susanna Esposito \\ Received: 27 January 2016; Accepted: 11 March 2016; Published: 22 March 2016
}

\begin{abstract}
Lipopolysaccharide (LPS) is a major virulence factor present in the outer membrane of Salmonella enterica serovar Typhimurium (S. Typhimurium). Outer membrane proteins (OMPs) from Salmonella show high immunogenicity and provide protection against Salmonella infection, and truncated LPS alters the outer membrane composition of the cell wall. In our previous study, we demonstrated that Salmonella mutants carrying truncated LPS failed to induce strong immune responses and cross-reaction to other enteric bacteria, due to their high attenuation and low colonization in the host. Therefore, we plan to investigate whether outer membrane proteins from Salmonella mutants with truncated LPS resulting from a series of nonpolar mutations, including $\Delta w a a C 12, \Delta w a a F 15, \Delta w a a G 42, \Delta r f a H 49, \Delta w a a I 43, \Delta w a a J 44, \Delta w a a L 46, \Delta w b a P 45$ and $\Delta w z y-48$, affect immunogenicity and provide protection against diverse Salmonella challenge. In this study, the immunogenicity and cross-protection efficiency of purified OMPs from all mutants were investigated to explore a potential OMP vaccine to protect against homologous or heterologous serotype Salmonella challenge. The results demonstrated that OMPs from three Salmonella mutants ( $\triangle$ waaC12, $\Delta w a a J 44$ and $\Delta$ waaL46) induced higher immune responses and provided good protection against homologous $S$. Typhimurium. The OMPs from these three mutants were also selected to determine the cross-protective efficacy against homologous and heterologous serotype Salmonella. Our results indicated that the mutant $\Delta$ waaC12 can elicit higher cross-reactivity and can provide good protection against $S$. Choleraesuis and $S$. Enteritidis infection and that the cross-reactivity may be ascribed to an antigen of approximately 18.4-30 kDa.
\end{abstract}

Keywords: lipopolysaccharide; outer membrane proteins; cross-protection

\section{Introduction}

Salmonella enterica, which is a Gram-negative intracellular bacterial pathogen, causes clinical epidemiology hazard in humans and animals [1-3]. Salmonella can be divided into two major groups based on the disease symptoms: typhoidal Salmonella and non-typhoidal Salmonella (NTS). It has been estimated that non-typhoidal Salmonella causes over 93.8 million cases of gastroenteritis and even 155,000 deaths annually on a global scale [4]. In developing regions, approximately 2.5 million cases of 
disease with approximately 4100 deaths per year result from NTS-mediated infections, most of which are of children younger than three years, individuals with malaria or human immunodeficiency virus (HIV)-infected adults [5,6]. S. Typhimurium, S. Enteritidis and S. Choleraesuis account for the majority of NTS cases worldwide [7].

Vaccination is an effective strategy for the prevention of Salmonella infection [8]. Currently, only two Salmonella vaccines have been licensed for human use, both targeted against $S$. Typhi for typhoid fever [9]. While more efforts have been undertaken to develop vaccines against non-typhoidal Salmonella, no licensed vaccines are currently available for human use [10]. Of the vaccine candidates, whole-cell killed vaccines or polysaccharide-conjugated sub-unit vaccines are serovar-specific and induce short-term immunity, and live vaccines possess the risk of restoring virulence in immunocompromised or elderly individuals [11]. In addition, those vaccines could not confer good cross-protection against multiple-serotype Salmonella challenge [12].

The outer membrane, the component of the cell envelope at the outer surface of Salmonella, contains a lipid layer consisting of phospholipids and lipopolysaccharides and anchors substantial amounts of outer membrane proteins (OMPs) [13-15]. OMPs isolated from $S$. Typhimurium have proven capable of conferring protection against lethal challenge with homologous Salmonella in mice, indicating that OMPs are good protective antigens [16-18]. Previous studies have further demonstrated that purified OMPs from Salmonella could mediate serotype-independent protection against homologous and heterologous Salmonella challenges $[19,20]$, and OMPs derived from rough mutants lacking complete lipopolysaccharide (LPS) structure and displaying the rough morphology were also able to induce cross-protective immune responses against heterologous challenge $[16,18]$. All of the above evidences indicate that OMPs from Salmonella have the potential for developing universal sub-unit vaccines to prevent homologous and heterologous Salmonella infections.

LPS is essential for the biosynthesis and assembly of the bacterial outer membrane [21,22]. Three different regions, including conserved lipid A, core oligosaccharide and variable $O$-antigen polysaccharide, constitute an entire LPS molecule [23]. The genes encoding the enzymes for synthesizing core oligosaccharide and $O$-antigen polysaccharide are clustered into two respective operon of waa or wba $[24,25]$, and deletion of each gene leads to an nonreversible incomplete core or $O$-antigen of LPS [26]. For example, the mutant strain $\triangle w a a L$ generates complete core oligosaccharide without $O$-antigen attached [26]. Truncated LPS can affect bacterial stability and outer membrane permeability, leading to the remodeling of the structure of the outer membrane and altering the outer membrane composition of the cell wall [26-28]. For example, the OMP profiles of Escherichia coli rough mutants were substantially distinct from the profiles of smooth strains [29-31]. Live Salmonella with truncated LPS should expose more OMPs to the host immune system, but live Salmonella with deep rough LPS was unable to colonize and persist in the host organs and induced poor immunogenicity against OMPs [26]. Therefore, we plan to investigate immunogenicity induced by OMPs from $S$. Typhimurium with truncated LPS of various lengths and to evaluate its cross-protection efficacy against infections with homologous and heterologous serotypes of Salmonella.

\section{Results}

\subsection{Mutant Construction and Phenotype Evaluation}

We used our published methods to construct a series of $S$. Typhimurium mutant strains using the parent strain S100, which was isolated from a duck infected with Salmonella [26] (Figures 1 and 2). We also constructed the additional mutants $\triangle w a a C 12$ and $\triangle w a a F 15$, and the PCR results confirmed that the deletions were successful (Figure 2A,B).

The LPS profile results showed that the $\triangle w a a C 12$ and $\triangle w a a F 15$ mutants had shorter lengths of LPS than the other mutants constructed in the previous study (Figure 2C) [26]. The LPS generated by the $\triangle w a a C 12$ mutant contained lipid A and 3-deoxy-D-mannooctulosonic acid (Kdo) moieties and migrated faster than the LPS generated by the $\triangle$ waaF15 mutant and other mutants, including $\Delta$ waaG42 
to $\Delta w z y-48$; LPS produced by the $\triangle w a a F 15$ mutant included lipid A, Kdo and one heptose moiety (Figure 2C). The mutants displayed distinct LPS lengths, from one $O$-antigen unit in the $\Delta w z y-48$ mutant to only Kdo in the $\Delta w a a C 12$ mutant.

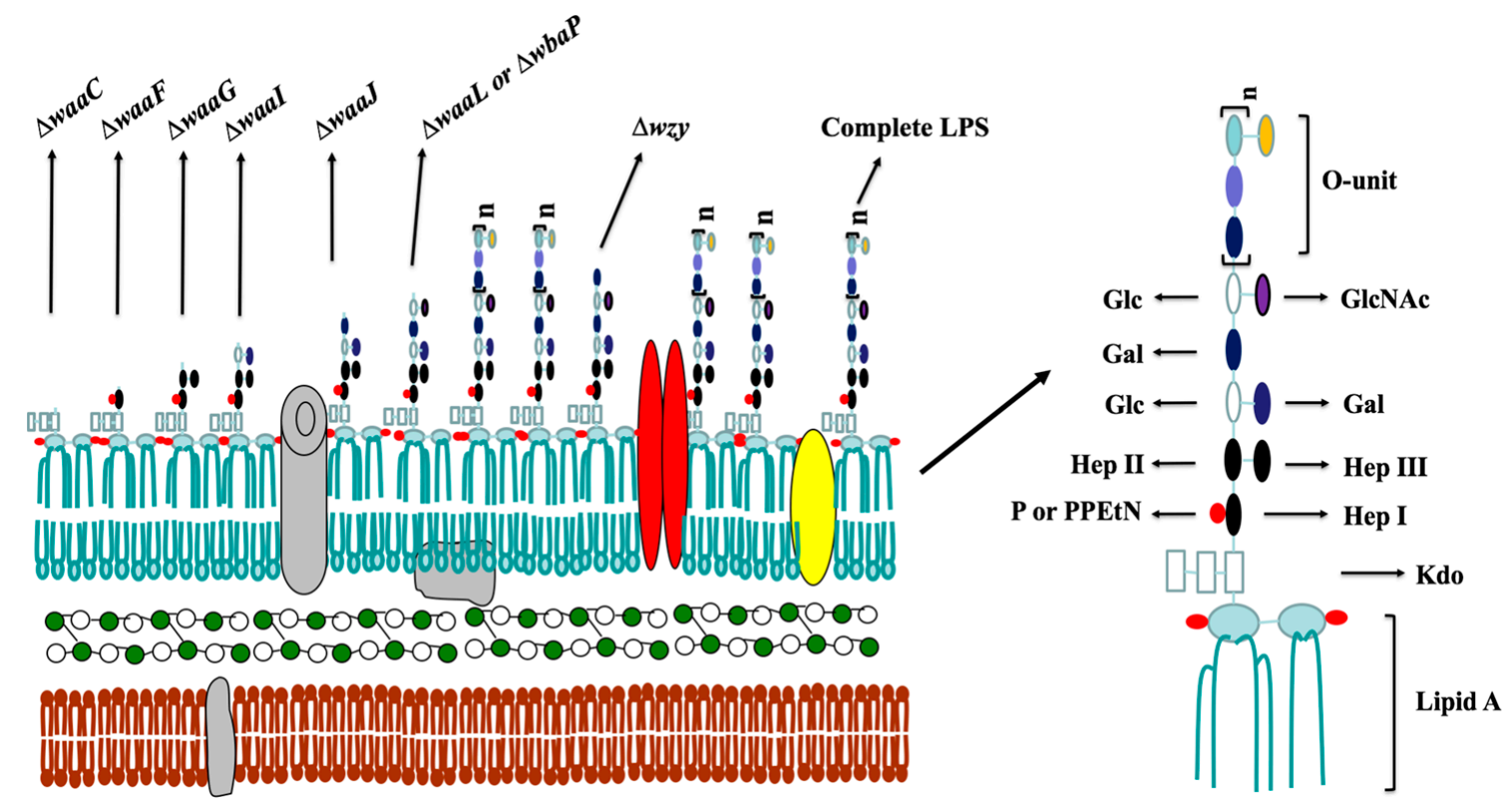

Figure 1. Schematic molecular model of $S$. Typhimurium cell wall structure. The Salmonella cell wall comprises the inner membrane, the periplasmic space filled with a gel-like matrix and the outer membrane. The inner membrane is the innermost component, whereas the outer membrane is the outermost impermeable structure, which is a bilayer consisting of a phospholipid layer on the inner side, and a lipopolysaccharide layer towards the outer side, as well as lipoproteins anchored into the membrane. Deletion of the specific gene responsible for lipopolysaccharide (LPS) synthesis would lead to truncation of LPS, thus resulting in the membrane rearrangement and altering the amounts and categories of lipoproteins. The figure represents the types of truncated LPS in this study. (Kdo, 3-deoxy-D-mannooctulosonic acid; PPEtN, pyrophosphorylethanolamine; Hep, heptose; GlcNAc, N-acetylglucosamine; Glc, glucose; Gal, galactose; P, phosphate). Deletion of waaC encoding heptosyltransferase I leads to a deep rough LPS structure carrying only Kdo-lipid A (Re); deletion of waaF encoding heptosyltransferase II results in a mutant generating a LPS structure with lipid A and a truncated inner core ( $\mathrm{Rd} 2)$; deletion of waa encoding a glycosyltransferase leads to the $\mathrm{Rd} 1$ type of LPS lacking the outer core, and consequently, waaI and waaJ mutants produce the truncated core phenotype of $\mathrm{Rb} 3$ and $\mathrm{Rb} 2$, respectively; deletion of both waaL encoding $\mathrm{O}$-antigen ligase and wbaP encoding Und-P galactose phosphotransferase leads to the production of core-lipid A ( $\mathrm{Ra})$ in the mutants; wzy encoding $\mathrm{O}$-antigen polymerase is one of three processing genes, the deletion of which results in a mutant generating a semi-rough LPS carrying a single $O$-antigen unit with a complete lipid A core, and the deletion of $r f a H$ encoding the transcriptional antiterminator leads to the production of the truncated core phenotype (Rb3).

\subsection{Preparation of $O M P S$}

As shown in Figure 3, the majority of proteins in the OMP profiles were between 35 and 45 kilodaltons (kDa), corresponding to the major porins, including OmpA, OmpC and OmpD [32,33]. The protein bands of low molecular weights ranging from 18.4 to $35 \mathrm{kDa}$ presented a slight divergence between the mutants and the wild-type strain (Figure 3). For instance, one up-regulated expression of the protein, the size of which was approximately $18.4 \mathrm{kDa}$, was observed in the $\Delta$ waaC12 mutant, and one just above the $25-\mathrm{kDa}$ protein band was present in $\Delta w b a P 45$ and $\Delta w z y-48$ mutants (red arrows). This result indicated that the genetic modification associated with the synthesis of LPS might result 
in the up- or down-regulated expression of diverse minor proteins by affecting the stability and permeability of the outer membrane [26-28].
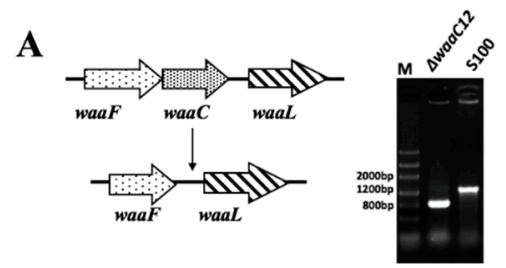

B
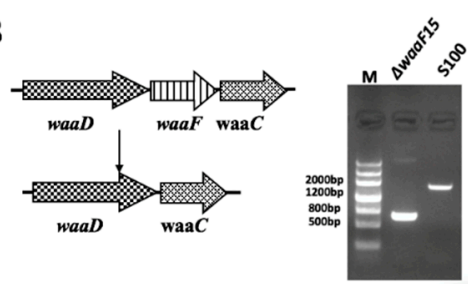

C

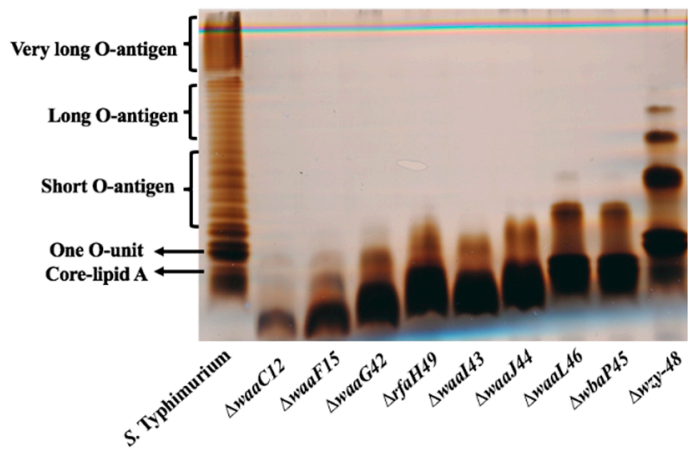

Figure 2. Mutant construction and LPS profiles. (A) Map of the deletion mutation of $\triangle$ waaC12 (left), and PCR verification of the $\triangle w a a C 12$ (right); (B) map of the deletion mutation of waaF15 (left) and PCR verification of the $\triangle$ waaC12 (right); and (C) LPS patterns of the mutants and the parent strain. LPS was visualized by silver straining on polyacrylamide gel electrophoresis (PAGE) gels. The expected location of $O$-antigen components and the core is shown on the left, and the $O$-unit is a repeating unit of the $O$-antigen.

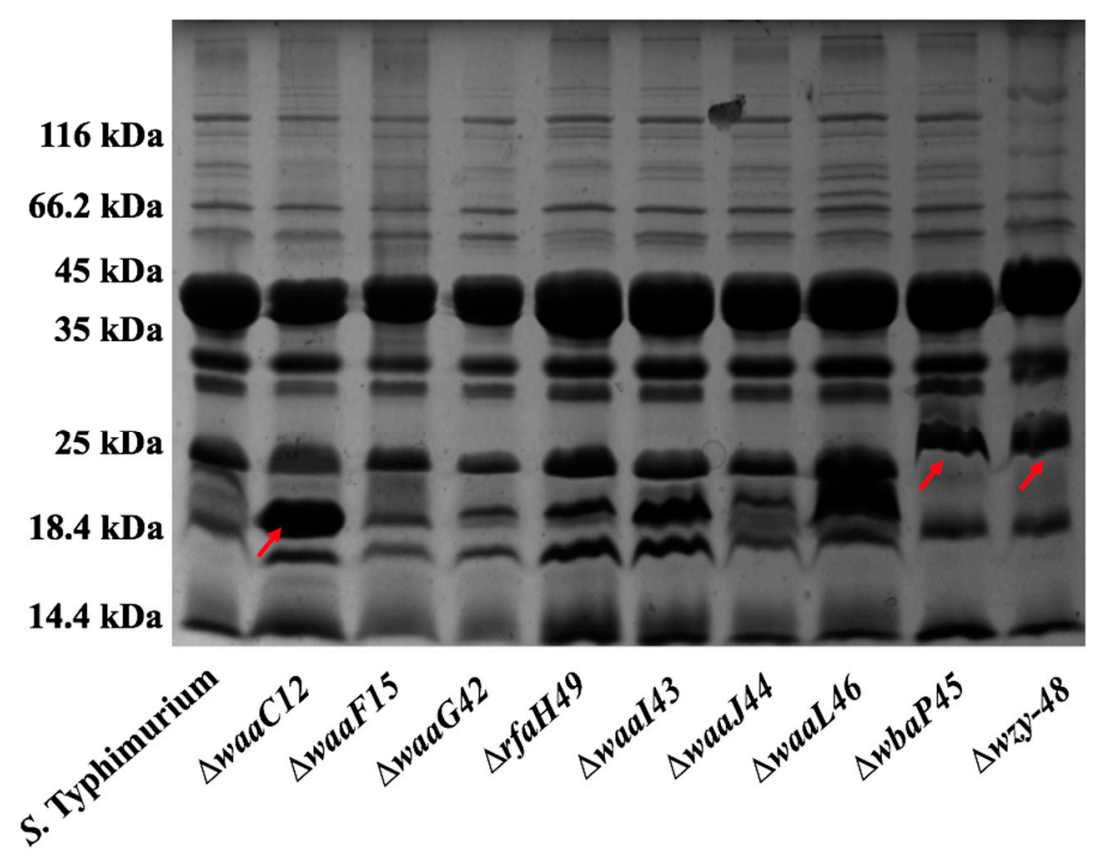

Figure 3. Outer membrane proteins' (OMPs) profile. OMPs purified from the parent strain and its mutants were separated by sodium dodecyl sulfate polyacrylamide gel electrophoresis (SDS-PAGE) on $12 \%$ gel and subjected to Coomassie brilliant blue staining. The mutant strains (from left to right): S100 (wild-type strain), S511 ( $\Delta$ waaC12), S512 ( $\Delta$ waaF15), S372 ( $\Delta$ waaG42), S377 ( $\Delta$ rfaH49), S373 ( $\Delta$ waaI43), S374 ( $\Delta$ waaj44), S376 ( $\Delta$ waaL46), S375 ( $\Delta w b a P 45)$, S378 ( $\Delta w z y-48)$. The red arrows represented the bands of differential proteins. 


\subsection{Evaluation of the Immunogenicity of OMPs from Wild-Type and Truncated LPS Salmonella}

To evaluate the immunogenicity induced by OMPs from diverse truncated LPS Salmonella, 10 groups of mice were immunized intranasally using purified OMPs from nine mutants and the wild-type S100 strain with $10 \mu \mathrm{g}$ OMPs in $5 \mu \mathrm{L}$ HEPES buffer and were then boosted with the same dose of the corresponding OMPs five weeks later. We measured the serum IgG, IgG1 and IgG2a antibody responses against OMPs from the wild-type S100 strain four and eight weeks after the first immunization (Figure 4). As shown in Figure 4, the OMPs from the wild-type S100 strain induced the highest level of IgG among all of the groups, while the OMPs from the $\Delta$ waaG42 mutant elicited the lowest IgG titer, significantly lower than the titers for the other groups $(p<0.01$ to 0.001$)$. At eight weeks (three weeks after the booster immunization), the $\Delta$ waaJ44, $\Delta w a a L 46, \Delta w b a P 45$ and $\Delta w z y$-48-induced anti-OMP IgG titers were similar to each other and significantly lower than the titer for the wild-type strain $(p<0.05)$. Interestingly, the titer of anti-OMP IgG induced by OMPs from the mutant $\Delta w a a C 12$, possessing the simplest structure of the "deep rough" phenotype LPS, was similar to that of the wild-type strain, with no significant difference.
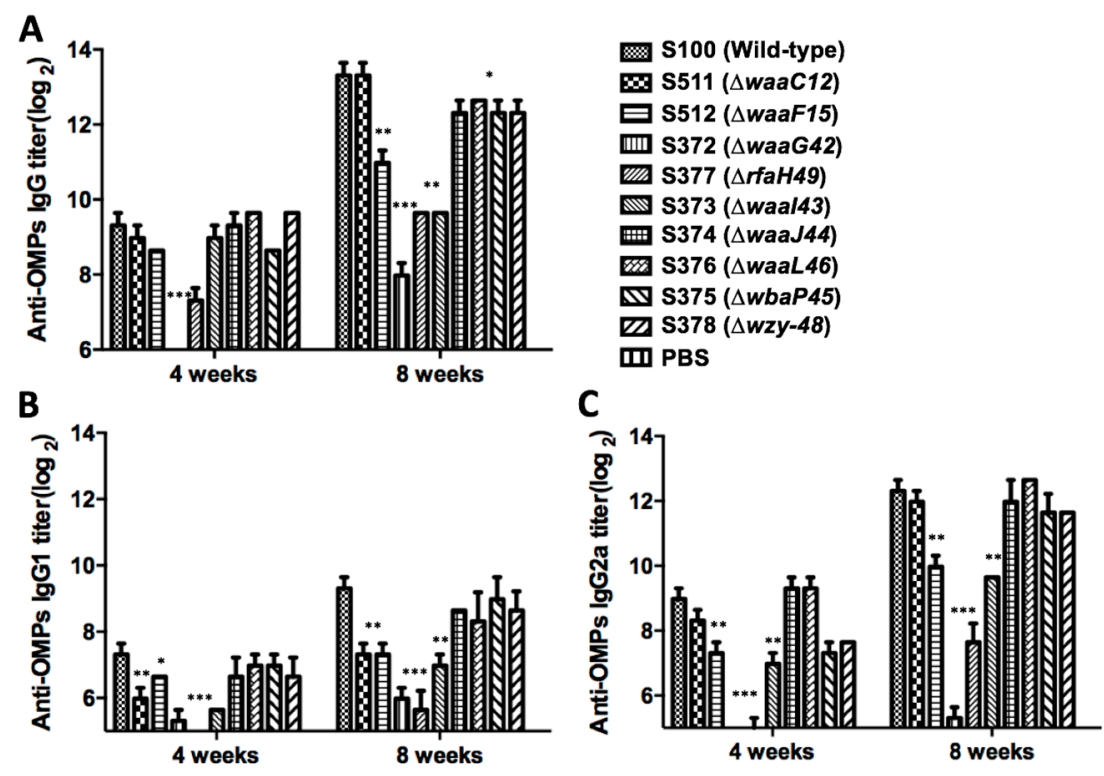

Figure 4. Serum antibody responses in mice immunized by the intranasal route. Total serum $\operatorname{IgG}$ specific for OMPs from $S$. Typhimurium (A), IgG1 specific for OMPs from $S$. Typhimurium (B) and IgG2a specific for OMPs from $S$. Typhimurium (C) were measured by enzyme-linked immunosorbent assay (ELISA). Each group has eight mice. The data represented the reciprocal anti-IgG antibody titer in pooled sera from mice immunized with OMPs from parent strain S100 and its mutants with truncated core or $O$-antigen at the indicated weeks after immunization. The error bars represented variations between triplicate wells. The mice were boosted at Week 5. ${ }^{* *} p<0.001 ;{ }^{* *} p<0.01 ;{ }^{*} p<0.05$; compared to titers from mice immunized with OMPs isolated from wild-type strain S100. No immune responses were detected to OMPs in mice immunized with PBS (reciprocal titer $<1: 50$ ). Immune responses (IgG, IgG1 and IgG2a) against OMPs from S. Typhimurium were below the detection level in the serum from mice immunized with OMPs from mutants $\Delta w a a G$ and $\Delta r f a H$ at four weeks (reciprocal titer $<1: 50)$.

We also determined the levels of anti-OMP IgG isotype subclasses IgG1 and IgG2a of serum from the mice of each group. As shown in Figure 4B,C, the IgG1 titers were similar to the IgG2a levels in the early phase (four weeks), but the IgG2a titers of all groups increased more rapidly than the IgG1 titers at eight weeks, indicating that the immune response exhibited a shift to a Th1-biased type. All groups of OMPs showed similar IgG1/IgG2a ratios, indicating that they elicited balanced 
Th1/Th2 responses. OMPs from the $\Delta w a a F 15, \Delta w a a G 42, \Delta r f a H 49$ and $\Delta w a a I 43$ groups showed poor immunogenicity, and the titers of IgG1 and IgG2a were lower than for the other groups at four and eight weeks $(p<0.05$ to 0.001$)$.

\subsection{Evaluation of Protection against Challenge by the S. Typhimurium Wild-Type Strain}

To investigate the effects of OMPs from LPS mutants on the protection efficacy, BALB/c mice were challenged via the oral route with $1 \times 10^{9} \mathrm{CFU}$ of $S$. Typhimurium strain S100 at five weeks after the booster immunization. Immunization with OMPs of $\Delta$ waaC12, $\Delta$ waaJ44, $\Delta$ waaL46, $\Delta w b a P 45$ and $\Delta w z y-48$ induced greater protective immunity than the other groups (Table 1), and the group with OMPs of the wild-type strain S100 showed 100\% protection against homologous Salmonella challenge. The mice of the $\Delta w a a F 15, \Delta w a a G 42, \Delta r f a H 49$ and $\Delta w a a I 43$ groups showed weak protection against Salmonella infection, and survival rates ranged from 25\% to 50\%, indicating that the OMPs from those mutants exhibited less protective immunity. All of the mice of the control group (PBS group) succumbed to $S$. Typhimurium strain $\mathrm{S} 100$ infection.

Table 1. Immunization with OMPs protected mice against oral challenge with $S$. Typhimurium strain S100.

\begin{tabular}{|c|c|}
\hline Groups & No. of Surviving Mice/Total No. of Mice \\
\hline S100 (wild-type) & $8 / 8(100 \%)$ \\
\hline $\mathrm{S} 511(\Delta w a a C 12)$ & $6 / 8(75 \%)$ \\
\hline $\mathrm{S} 512(\Delta w a a F 15)$ & $4 / 8(50 \%)$ \\
\hline $\mathrm{S} 372(\Delta w a a G 42)$ & $2 / 8(25 \%)$ \\
\hline $\mathrm{S} 377(\Delta r f a H 49)$ & $2 / 8(25 \%)$ \\
\hline S373 ( $\Delta$ waal43) & $4 / 8(50 \%)$ \\
\hline S374 ( $\Delta$ waa 44$)$ & $6 / 8(75 \%)$ \\
\hline S376 ( $\Delta$ waaL46) & $8 / 8(100 \%)$ \\
\hline $\mathrm{S} 375(\triangle w b a P 45)$ & $6 / 8(75 \%)$ \\
\hline $\mathrm{S} 378(\Delta w z y-48)$ & $6 / 8(75 \%)$ \\
\hline Phosphate Buffered Saline (PBS) & $0 / 8(0 \%)$ \\
\hline
\end{tabular}

\subsection{Evaluation of Cross-Reactivity with OMPs from Heterologous Serotype Salmonella}

To evaluate the cross-reactivity of serum antibodies from the mice immunized using OMPs of wild-type and truncated LPS Salmonella mutants, we detected the antibody responses of pooled serum from mice immunized with OMPs isolated from all mutant strains against purified OMPs from multiple Salmonella strains, including S. Choleraesuis and S. Enteritidis. The IgG levels of the $\Delta w a a C 12$ groups were higher than the levels in the parent strain group against the OMPs from $S$. Choleraesuis and $S$. Enteritidis, and both showed significant differences compared to the parent strain $(p<0.05)$ (Figure 5). The $\Delta w a a J 44, \Delta w a a L 46, \Delta w b a P 45$ and $\Delta w z y$-48 groups also elicited higher reactivities than the wild-type $\mathrm{S} 100$ group against OMPs isolated from $S$. Choleraesuis and $S$. Enteritidis, and only the $\Delta$ waaj44 group showed a significant difference compared to the S100 group $(p<0.05)$.

Furthermore, the competitive ELISA was used to confirm the cross-reactivity of OMPs from the wild-type and the truncated LPS mutant strains. The $\triangle w a a C 12$ and $\triangle$ waaJ 44 mutants elicited significant cross-reactivity of $S$. Typhimurium OMPs against OMPs from $S$. Choleraesuis $(p<0.001)$; however, the $\Delta$ waaL46 group had no significant difference of cross-reactivity compared to the wild-type group (Figure 6A). OMPs from all three mutants presented the induction of cross-reactivity against OMPs from $S$. Enteritidis $(p<0.001$ or 0.05 ) (Figure $6 \mathrm{~B})$. The competitive ELISA results further proved the increased cross-reactivity of OMPs from truncated LPS mutants against heterologous Salmonella. 


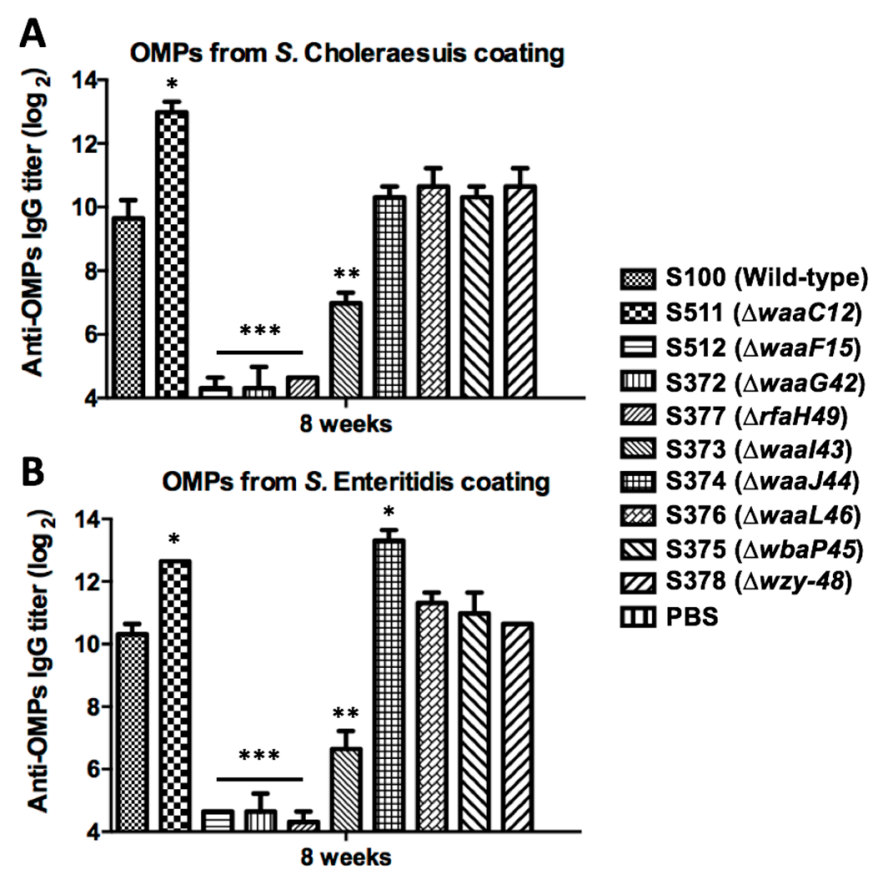

Figure 5. IgG cross-reactivity against OMPs from other Salmonella serogroups. The sera were obtained from mice $(n=8)$ immunized with OMPs from the parent strain and its mutants with the truncated core or $O$-antigen at eight weeks after the primary immunization and were pooled to evaluate $\operatorname{IgG}$ cross-reaction against OMPs isolated from heterologous diverse Salmonella, including $S$. Choleraesuis (A) and S. Enteritidis (B). The error bars represent variations from triplicate wells. ${ }^{* * *} p<0.001$; ** $p<0.01 ;{ }^{*} p<0.051$; compared to titers from mice immunized with OMPs from parent strain S100.

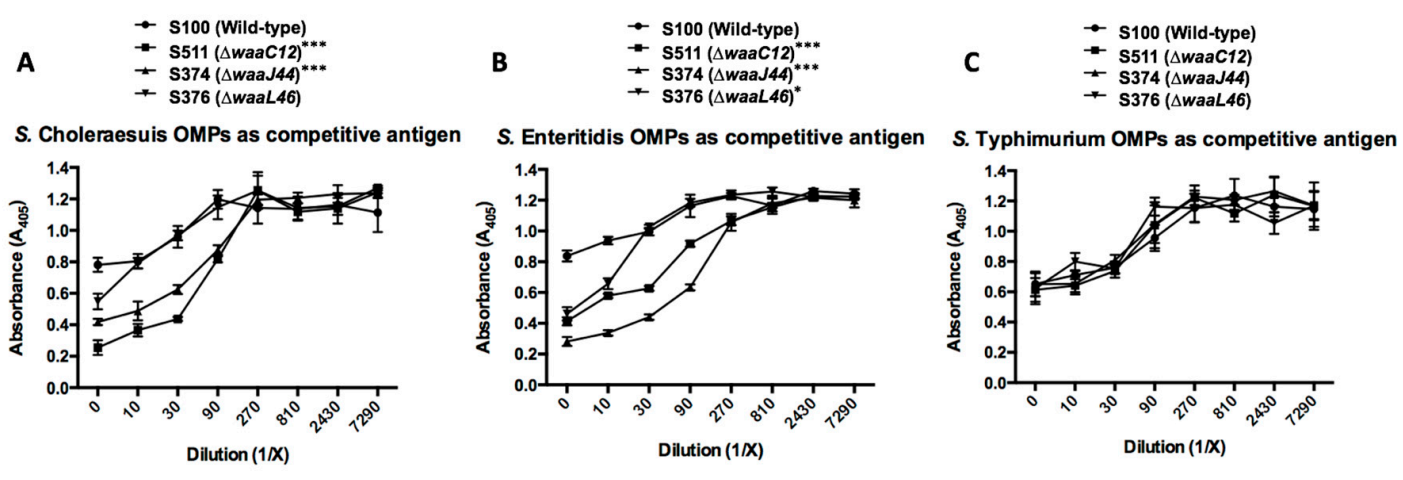

Figure 6. Competitive ELISA to confirm the cross-reactivity of OMPs from the truncated LPS mutants against heterologous Salmonella. OMPs isolated from $S$. Typhimurium were incubated in the plate as the coating antigen. OMPs from $S$. Choleraesuis (A) or $S$. Enteritidis (B) as the competitive antigen and OMPs from $S$. Typhimurium (C) as the control competitive antigen diluted from 1/10 to 1/7290 (Dilution, $1 / X)$ were incubated in wells. The sera were obtained from mice $(n=8)$ immunized with OMPs from the parent strain and its mutants at eight weeks after the primary immunization. The error bars represent variations from triplicate wells. ${ }^{* *} p<0.001$; $p<0.05$; compared to titers from mice immunized with OMPs from the parent strain S100.

\subsection{Evaluation of Cross-Protection against Heterologous Serotype Salmonella}

To investigate the protection efficacy against challenges by different Salmonella serotypes, immunized mice of twelve groups, including nine experimental groups and three control groups, were independently challenged via oral administration of $10^{9}\left(10^{4} \times \mathrm{LD}_{50}\right), 10^{7}\left(\sim 10^{2} \times \mathrm{LD}_{50}\right)$ or 
$10^{7}\left(\sim 10^{2} \times \mathrm{LD}_{50}\right)$ CFU of S100 (S. Typhimurium), S246 (S. Enteritidis) or S340 (S. Choleraesuis), respectively. This experiment was performed twice. The results from the two experiments were similar and were pooled for analysis. As shown in Figure 7A, the protection rate against $S$. Typhimurium was consistent with the previous results (Table 1), and OMPs isolated from the wild-type S100 strain induced a strong protective immunity against $S$. Typhimurium. Immunization with OMPs from the $\Delta w a a C 12, \Delta w a a J 44$ and $\Delta w a a L 46$ mutants provided $66.7 \%(8 / 12)$ protection for mice after $S$. Choleraesuis challenge, and they could induce higher protection efficacy than immunization with OMPs from the parent strain S100 (Figure 7B) $(p=0.46)$. For $S$. Enteritidis (Figure 7C), the degrees of protection provided among various groups were different. The best protection levels were provided by the $\Delta$ waaC12, which elicited $83 \%(10 / 12)$ survival and exhibited higher protection than the wild-type strain. Interestingly, the $\Delta w a a L 46$ group induced lower protection $(50 \%, 6 / 12)$ than the S100 group $(66 \%, 8 / 12)$, indicating that the protection efficacy of the OMPs isolated from the mutant $\Delta w a a L 46$ was not consistent with the immunogenic capability (Figure 7).
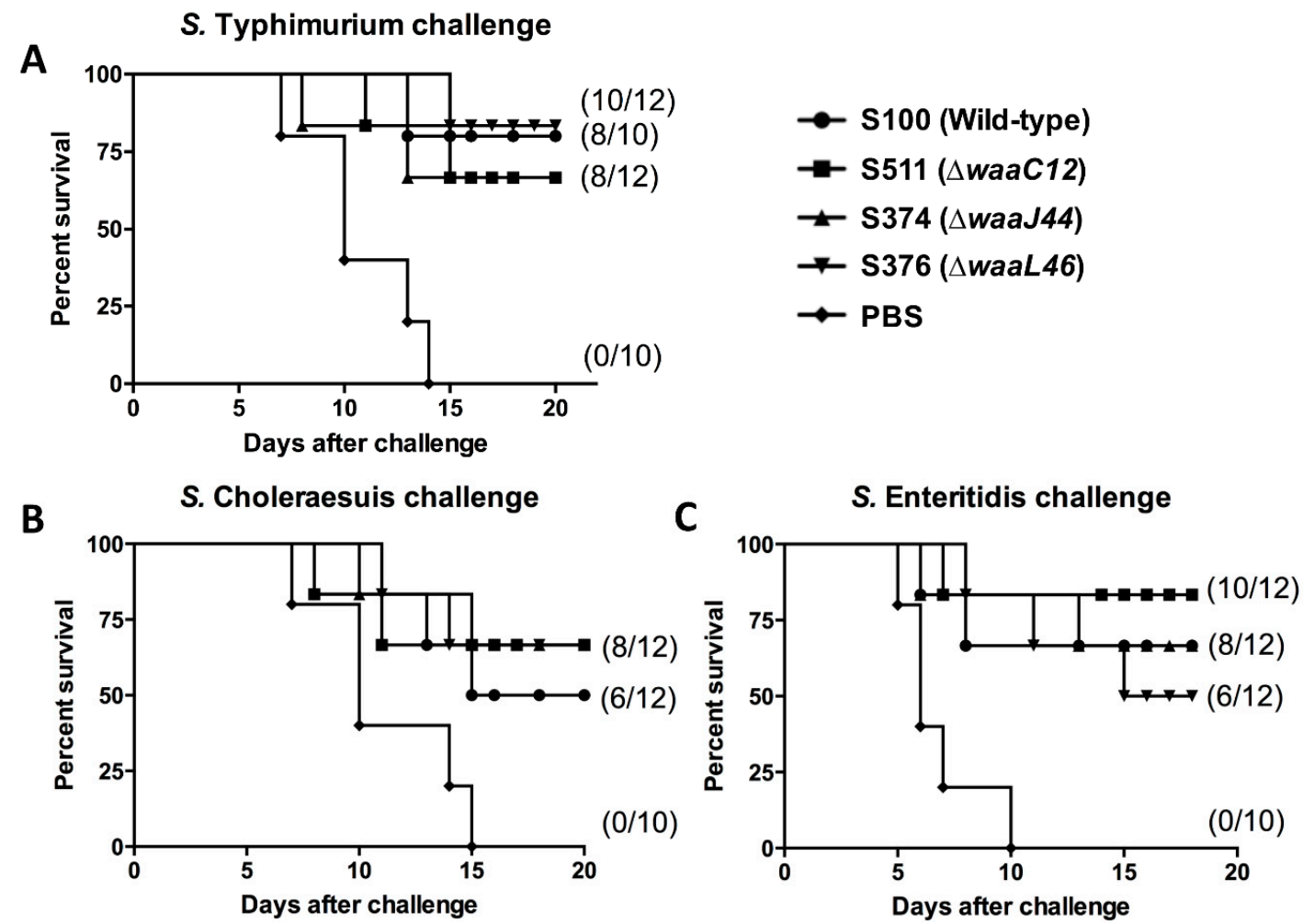

Figure 7. Cross-protective efficacy induced by OMPs. Ten (control) or 10 to 12 (vaccine) BALB/c mice per group were intranasally immunized twice at four-week intervals with OMPs isolated from the indicated Salmonella mutants. The immunized mice were orally challenged with $10^{9}, 10^{7}$ and $10^{7} \mathrm{CFU}$ of S100 (S. Typhimurium) (A), S340 (S. Choleraesuis) (B) and S246 (S. Enteritidis) (C), respectively, at eight weeks after the first immunization. Mortality was monitored for three weeks after challenge. The data were combined from the two separate experiments, which showed similar results, and the numbers in parentheses referred to the number of surviving mice and the total number of mice per group. All vaccine groups were significantly different from the PBS control $(p<0.01)$. There was no significant difference in protection among the other groups.

\section{Discussion}

Due to the emergence of multiple drug resistance in Salmonella, Salmonellosis is currently difficult to control [34-36]. Vaccination is a powerful tool for the control of this disease. Traditional subunit vaccines consisting of single protein antigens have limited vaccine efficacy and protection due to 
antigenic variation among Salmonella strains [8]. Therefore, vaccines containing OMPs capable of inducing a cross-protective immune response against multiple serotypes of Salmonella may be a good option for developing vaccines against multiple Salmonella serovars. In our previous study, we demonstrated that Salmonella mutants carrying truncated LPS were not good live vaccines, as they failed to induce strong immune responses and cross-reactivity to other enteric bacteria [26]. In this study, we systematically investigated the immunogenicity and cross-protection efficiency of OMPs purified from mutants, including $\Delta w a a C 12, \Delta w a a F 15, \Delta w a a G 42, \Delta r f a H 49, \Delta w a a I 43, \Delta w a a J 44, \Delta w a a L 46$, $\Delta w b a P 45$ and $\Delta w z y-48$, and discovered potential OMP vaccines to protect against homologous or heterologous serotype Salmonella infection.

In this study, we used the method of detergent-insoluble isolation for OMPs preparation, and this method was the initial extraction of the outer membrane complex, composed of a large amount of OMPs, a small amount of LPS and other cell membrane components [37,38]. Additionally, OMPs purified from several Gram-negative bacteria following this method were commonly used to evaluate its potential as subunit vaccines $[39,40]$; therefore, we consider this outer membrane complex to be OMPs.

It has been demonstrated that LPS structure can affect the outer membrane compositions of bacteria [27,28]. Based on examples from E. coli studies, the OMP profiles of $E$. coli rough mutants were substantially distinct from the profiles of smooth strains [29-31]. In this study, differences in the OMP profiles of mutants with truncated and smooth LPS were also observed, but it seems that truncated LPS did not significantly influence the composition of the OMPs (Figure 3).

OMPs from different Salmonella and parent strains were administered to the mice via intraperitoneal and intranasal routes. Vaccination by the intraperitoneal route caused severe symptoms in mice, which might result from toxic lipid A [41,42]; therefore, we did not show those results in this study. The purpose of this study was to investigate the immunogenicity and protection efficacy conferred by OMPs from $S$. Typhimurium mutants with diverse truncated LPS and to discover the best OMPs for developing a universal subunit vaccine for multiple Salmonella infection. We selected three Salmonella serotypes to evaluate the immune responses and challenges, including $S$. Typhimurium, belonging to the B1 serotype group, which is the natural strain infecting mice and other animals, and was used for OMP preparation [43]; $S$. Enteritidis, belonging to the D1 serotype group, whose natural host is chicken and poultry [44,45]; and $S$. Choleraesuis, belonging to the C1 serotype group, whose natural host is pig [46,47]. These three Salmonella serotypes contribute to the majority of non-typhoidal Salmonella (NTS) cases worldwide [6], and they are able to establish systemic infection in mice after oral administration. Therefore, we selected the mouse model to determine the cross-protection conferred by OMPs from various LPS mutants after $S$. Typhimurium, $S$. Choleraesuis and $S$. Enteritidis infection.

The immune responses induced in mice by OMPs from various LPS mutants were diverse, showing that OMPs isolated from wild-type strain Salmonella could induce the highest antibody levels against OMPs, and OMPs from the $\triangle w a a G 42$ mutant induced the least antibody levels against OMPs from $S$. Typhimurium (Figures 4 and 5). IgG antibodies from mice immunized with OMPs from $\Delta w a a C 12$ and $\Delta$ waa 44 mutants were significantly more reactive against OMPs from $S$. Choleraesuis and $S$. Enteritidis than IgG antibodies from mice immunized with wild-type OMPs, and IgG antibodies from mice immunized with OMPs from $\Delta w a a L 46, \Delta w b a P 45$ and $\Delta w z y-48$ mutants showed the same reactions against OMPs from $S$. Choleraesuis and $S$. Enteritidis as IgG antibodies from mice immunized with OMPs from the wild-type strain (Figure 5), indicating that the $O$-antigen polysaccharide in OMPs from the wild-type $S$. Typhimurium will also contribute to the induction of immune responses, which was also supported by the protection rate after challenge with wild-type $S$. Typhimurium, showing that OMPs from wild-type $S$. Typhimurium conferred a $100 \%$ protection rate, while OMPs from other mutants conferred lower protection efficacies (Table 1). The OMPs isolated from $\triangle$ waaL46 and $\triangle w b a P 45$ mutants generating the same LPS moiety of lipid A with the entire core did not provide the same protection rate against wild-type $S$. Typhimurium challenge (Table 1), indicating that protection 
capacity provided by OMPs from truncated LPS mutants may primarily be ascribed to induced immunity to OMPs, not to truncated LPS [48].

Based on the results obtained from the first animal experiments, we selected OMPs from the mutants $\Delta w a a C 12, \Delta w a a J 44$ and $\Delta w a a L 46$ to evaluate their capacity to induce cross-protection against multiple Salmonella infections. As immunized OMPs purified from Salmonella and its mutant derivatives would be contaminated by small amounts of various truncated LPS possessed by Salmonella species, these conserved oligosaccharides might only confer limited cross-protection compared to conserved OMPs during the smooth Salmonella infection [48]. For examples, in our study, $S$. Typhimurium and $S$. Enteritidis share $\mathrm{O} 1$ and $\mathrm{O} 12 \mathrm{O}$-antigen epitopes in their $\mathrm{O}$-antigen polysaccharide $[49,50]$; OMPs purified from wild-type $S$. Typhimurium, which was contaminated by wild-type LPS carrying $\mathrm{O} 1$ and $\mathrm{O} 12$ epitopes, did not provide better protection against $S$. Enteritidis infection than OMPs from $\triangle w a a C 12$ and $\Delta w a a J 44$ mutants (Figure 7). Oligosaccharides isolated from rough $S$. Gallinarum 9R, which, coupled to bovine serum albumin (BSA) directly, induced cross-reactivity between serum and heterologous smooth LPS of $S$. Enteritidis, but did not provide protection against lethal challenge of $S$. Enteritidis [51], indicated that truncated LPS in vaccines plays minor roles to protect against the pathogenic smooth LPS Salmonella infection; the evidence supporting our notion also came from earlier studies in that antibodies to the Rc or Re core of LPS only provided a limited spectrum of protection, as these antisera only have a limited ability to react with smooth LPS [52-54].

We observed that OMPs from the $\Delta w a a C 12$ mutant were able to promote cross-reaction and to provide good protection against $S$. Choleraesuis and $S$. Enteritidis infections (Figures 5-7). This cross-protection conferred by the crude OMPs from the waaC mutant would contribute primarily to the cross-protective OMPs, where contamination of lipid A with Kdo in OMPs may function as an optimal adjuvant and enhanced the immune responses to OMP antigens [41,42]; the components of OMPs from waaC mutant serving as cross-protective antigens also need to be determined in a future study.

In summary, we systematically investigated the immunogenicity and protective efficacy of crude OMPs isolated from truncated LPS Salmonella mutant strains and found that OMPs from the mutant $\triangle w a a C 12$ in our tested OMPs could elicit enhanced cross-protective immunity against heterologous serotype Salmonella.

\section{Materials and Methods}

\subsection{Bacterial Strains, Plasmids, Media and Growth Conditions}

All strains and plasmids associated with this study are listed in Table 2. Salmonella Typhimurium (S. Typhimurium) and Escherichia coli (E. coli) were grown in Luria-Bertani (LB) [55] broth or agar or nutrient broth (Difco, Detroit, MI, USA) at $37^{\circ} \mathrm{C}$. The growth of $\triangle$ asd strains needed to be added to $50 \mu \mathrm{g} / \mathrm{mL}$ of diaminopimelic acid (DAP) [56]. Sucrose-LB agar (5\% concentration) was used for sacB gene-based counter selection in mutant strains' construction.

Table 2. Bacterial strains and plasmids used in this study.

\begin{tabular}{ccc}
\hline Strains or Plasmids & Description & Source \\
\hline & Strains & \\
\hline S100 & S. Typhimurium, clinical isolate from duck & IPVM $^{*}$ \\
\hline S511 & $\Delta$ waaC12 & This work \\
\hline S512 & $\Delta$ waaF15 & This work \\
\hline S372 & $\Delta$ waaG42 & {$[26]$} \\
\hline S377 & $\Delta r f a H 49$ & {$[26]$} \\
\hline S373 & $\Delta$ waal43 & {$[26]$} \\
\hline
\end{tabular}


Table 2. Cont

\begin{tabular}{|c|c|c|}
\hline Strains or Plasmids & Description & Source \\
\hline \multicolumn{3}{|c|}{ Strains } \\
\hline S374 & $\Delta w a a J 44$ & [26] \\
\hline S376 & $\Delta w a a L 46$ & [26] \\
\hline S375 & $\Delta w b a P 45$ & [26] \\
\hline S378 & $\Delta w z y-48$ & [26] \\
\hline S246 & S. Enteritidis, clinical isolate from chicken & IPVM \\
\hline S340 & S. Choleraesuis, clinical isolate from pig & IPVM \\
\hline E. coli & - & - \\
\hline$\chi 7232$ & 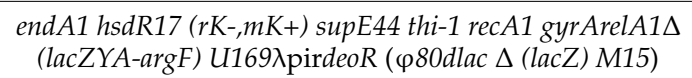 & [57] \\
\hline$\chi 7213$ & $\begin{array}{l}\text { thi-1 thr-1 leuB6 glnV44 tonA21 lacY1 recA1 } \\
\text { RP4-2-Tc:: } \mu \lambda \text { pir } \triangle a s d A 4 \Delta z h f-2:: \operatorname{Tn} 10\end{array}$ & [57] \\
\hline \multicolumn{3}{|c|}{ Plasmids } \\
\hline pYA4278 & Suicide plasmid (pRE112) & [26] \\
\hline pQK256 & For deletion of $r f a C$ & This work \\
\hline pQK257 & For deletion of $r f a F$ & This work \\
\hline
\end{tabular}

* IPVM: Institute of Preventive Veterinary Medicine at the Sichuan Agricultural University in China.

\subsection{Construction of Plasmids and Mutations}

The primers designed in this study are listed in Table S1. The protocol of DNA manipulations was performed as previous described [58]. Transformation of E. coli was done by electroporation. Positive clones were selected on LB agar plates containing appropriate antibiotics. Asd $^{+}$plasmids were selected by LB agar plates.

We followed the published methods to construct Salmonella mutants from $\Delta w a a G 42$ to $\Delta w z y-48$ based on parent $S$. Typhimurium $S 100$ [26]. For construction of the $\Delta w a a C$ mutation, two pairs of primers, waaC- $1 \mathrm{~F} / \mathrm{waaC}-1 \mathrm{R}$ and $\mathrm{waaC}-2 \mathrm{~F} / \mathrm{waaC}-2 \mathrm{R}$, were used for the waaC deletion and used to amplify approximately 350-bp upstream and downstream fragments of gene waaC, respectively, from the S100 (S. Typhimurium); then, two fragments were joined by PCR using primers waaC-1F/waac-2R. The resulting PCR product was added to the terminal A by using the LA Taq enzyme (Takara, Dalian, China) and then was co-incubated with the T-terminal pYA4278 vector, which was digested by AhdI enzyme, resulting in plasmid pQK256. The construction of pQK257 for waaF gene deletion used the same strategy as waaC gene deletion.

$\Delta w a a C 12$ and $\Delta w a a F 15$ mutations were independently introduced into $S$. Typhimurium by the suicide plasmid method [59]. Briefly, S100 (S. Typhimurium) bacterial cultures were conjugated with E. coli $\chi 7213$ harboring suicide plasmids $\mathrm{pQK} 256$ (for $\Delta w a a C$ ) or $\mathrm{pQK} 257(\Delta w a a F)$ as the ratio of 1:1.5 on the LB agar plate. After $24 \mathrm{~h}$ of incubation, the bacteria cell complexes were scratched and streaked on the LB agar plate containing $25 \mu \mathrm{g} / \mathrm{mL}$ chloramphenicol $(\mathrm{Cm})$; the next day, the single colony was picked up and grown on the plates with $\mathrm{Cm}$ antibiotic, and the single crossover strains was grown in the fresh LB for $4 \mathrm{~h}$, was diluted to LB by a suitable ratio and spread on the LB plates containing $5 \%$ sucrose overnight at room temperature. The LB plate and LB plate containing $\mathrm{Cm}$ antibiotic were used to screen the positive colony; the colony that cannot grow on the LB plate containing $\mathrm{Cm}$ antibiotic will be identified by colony PCR. The other mutation $\triangle$ waaF could be introduced into S100 to generate the mutant $\mathrm{S} 512$ by the same strategy as mutant $\Delta w a a C$. 


\subsection{The Lipopolysaccharide (LPS) Profile of Salmonella Mutant Strains}

LPS profiles were determined by the previous method as described [60]. Briefly, $2 \mathrm{~mL}$ of overnight cell culture were pelleted and resuspended in $150 \mu \mathrm{L}$ of Dissociation Buffer A (0.5 M Tris-Cl pH 6.8, $10 \%$ glycerol, $10 \%$ SDS, $5 \% \beta$-mercaptoethanol); then, the samples were boiled for $10 \mathrm{~min}$. After cooling at room temperature, the samples were centrifuged for $15 \mathrm{~min}$. The supernatant was diluted 1:10 (10 into $90 \mu \mathrm{L})$ into Dissociation Buffer B (0.5 M Tris-Cl pH 6.8, 10\% glycerol, $0.05 \%$ bromophenol blue), and $1 \mu \mathrm{L} 20 \mathrm{mg} / \mathrm{mL}$ proteinase K (Sigma-Aldrich, St. Louis, MO, USA) was added into the dilution and incubated at $37^{\circ} \mathrm{C}$ for $1 \mathrm{~h}$. After that, the samples were separated on $12 \%$ gels (sodium dodecyl sulfate polyacrylamide gel electrophoresis (SDS-PAGE)) and stained by silver staining.

\subsection{Outer Membrane Proteins (OMPs) Purification}

The method of preparation of OMPs was based on the method used by Carlone and Thomas [37]. Briefly, $500 \mathrm{~mL}$ of overnight culture were harvested and resuspended in $25 \mathrm{~mL}$ of $10 \mathrm{mM}$ HEPES buffer ( $\mathrm{pH}$ 7.4) on ice. The cells were lysed by FRENCH Pressure (Thermo IEC, Needham Heights, MA, USA); the samples were centrifuged $\left(15,600 \times g, 2 \mathrm{~min}, 4{ }^{\circ} \mathrm{C}\right)$ for removing the unbroken cells; the supernatants were transferred into a new tube and centrifuged $\left(15,600 \times g, 30 \mathrm{~min}, 4^{\circ} \mathrm{C}\right)$. The

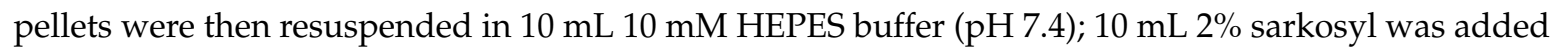
into the supernatant and mixed well and then incubated for $30 \mathrm{~min}$ at room temperature with gentle shaking on a vortex Genie. After centrifugation $\left(15,600 \times g, 30 \mathrm{~min}, 4^{\circ} \mathrm{C}\right)$, the pellets were washed once by $20 \mathrm{~mL} 10 \mathrm{mM}$ HEPES buffer (pH 7.4) and finally resuspended in $1 \mathrm{~mL}$ Phosphate Buffered Saline (PBS) buffer ( $\mathrm{pH}$ 7.4). Purified OMPs were stored at $-80^{\circ} \mathrm{C}$.

The concentrations of OMPs were measured by the BCA protein assay kit (Thermo Pierce, Rockford, IL, USA), and $10 \mu \mathrm{g}$ OMPs were analyzed by SDS-PAGE and strained by Coomassie brilliant blue (Bio-Rad, Richmond, CA, USA).

\subsection{Animal Experiments}

Animal research was carried out in accordance with the Animal Welfare Act and regulations related to animal experiments (Ya'an, China; Approval No. 2011-028). The principle stated in the Guide for the Care and Use of Laboratory Animals was followed. The animal care protocols were approved by Sichuan Agricultural University. All efforts were made to minimize animal suffering during the experiments.

BALB/c mice of 6 weeks of age were used for all of the animal experiments and purchased from the Dashuo Biotechnology Co., Ltd. (Chengdu, China). Eight to twelve mice for each group were immunized intranasally on Day 0 and boosted at Week 5 with $10 \mu \mathrm{g}$ OMPs in $5 \mu \mathrm{L}$ PBS buffer per mice, and $5 \mu \mathrm{L}$ PBS buffer served as the control. The blood samples were collected at the interval of two weeks after the immunization.

To determine immune response induced by OMPs isolated from Salmonella strains, including $\Delta w a a C 12, \Delta w a a F 15, \Delta w a a G 42, \Delta r f a H 49, \Delta w a a I 43, \Delta w a a J 44, \Delta w a a L 46, \Delta w b a P 45, \Delta w z y-48$ and S100, the mice of eleven groups were immunized by intranasal route with OMPs and the negative control. Five weeks after the booster immunization, the mice were challenged with $10^{9}$ colony-forming units (CFU) of S100 (S. Typhimurium) in $20 \mu \mathrm{L}$ buffered saline with $0.01 \%$ gelatin (BSG) by the oral route for determining the protection rates. Fifty percent lethal death $\left(\mathrm{LD}_{50}\right)$ of $\mathrm{S} 100$ is about $10^{5} \mathrm{CFU}$ using the mouse model. The mice were monitored daily for 30 days after challenge.

To evaluate the cross-protective ability conferred by immunization of OMPs from diverse Salmonella strains, we selected three Salmonella mutants for the animal experiment, including $\Delta$ waaC12, $\Delta w a a J 44$ and $\Delta w a a L 46$, the OMPs of which provided better protection efficacy against the challenge of $S$. Typhimurium and immune responses against OMPs from $S$. Typhimurium, $S$. Enteritidis and S. Choleraesuis. Five weeks after the booster immunization, the mice were challenged with $10^{9}, 10^{7}$ 
and $10^{7}$ CFU of S100 (S. Typhimurium), S246 (S. Enteritidis) and S340 (S. Choleraesuis) in $20 \mu \mathrm{L}$ BSG by the oral route, respectively. The challenged mice were monitored daily for 30 days.

\subsection{Analysis of Antibody Response in Mice}

The enzyme-linked immunosorbent assay (ELISA) method was used to analyze the antibody responses induced by OMPs [61]. Briefly, $2 \mu \mathrm{g}$ of OMPs from $S$. Typhimurium (S100), S. Enteritidis (S246) or S. Choleraesuis (S340) in $100 \mu \mathrm{L}$ sodium carbonate bicarbonate coating buffer (pH 9.6) were used to coat each well of the 96-well plates and then incubated overnight at $4{ }^{\circ} \mathrm{C}$. The plate was washed 3 times with PBST (PBS with 0.1\% Tween 20) and then blocked with 2\% bovine serum albumin (BSA) (Sigma-Aldrich) solution. After incubation of $2 \mathrm{~h}$ at room temperature, a $100-\mu \mathrm{L}$ volume of serially-diluted sample (serum dilution started at 1:50) was added to triplicate individual wells and incubated for $1 \mathrm{~h}$ at room temperature and then washing with PBST 3 times; biotinylated goat anti-mouse IgG, IgG1 or IgG2a (Southern Biotechnology Inc., Birmingham, AL, USA) was added in each well, and then, the wells were developed with a streptavidin-alkaline phosphatase conjugate (Southern Biotechnology, Inc., Birmingham, AL, USA) and detected using p-nitrophenylphosphate substrate (Sigma-Aldrich) in diethanolamine buffer ( $\mathrm{pH}$ 9.8). Absorbance was taken at $405 \mathrm{~nm}$ using an automated ELISA plate (Bio-Rad iMark Microplate Reader, Hercules, CA, USA) with suitable time. The data A405, which had 0.1 higher than the PBS control values, was considered positive.

The competitive ELISA of serum IgG antibody between OMPs from $S$. Typhimurium and $S$. Enteritidis or $S$. Choleraesuis was used to confirm the cross-reactivity of the OMPs from different LPS mutants conferring strong immunity and good protective efficacy [62]. Two micrograms per well of the OMPs isolated from $S$. Typhimurium were coated in plates, and a $100-\mu \mathrm{L}$ volume of a 50 -fold diluted serum was added to the wells in triplicate. After $1 \mathrm{~h}$ of incubation at room temperature, OMPs from $S$. Enteritidis or $S$. Choleraesuis as the competitive antigen and OMPs from $S$. Typhimurium as the control competitive antigen diluted in several dilutions from 10-fold to 7290 -fold were incubated in each well for $2 \mathrm{~h}$ at $37^{\circ} \mathrm{C}$. The absorbance at $405 \mathrm{~nm}$ was read in an automated ELISA plate (Bio-Rad iMark Microplate Reader, USA).

\subsection{Statistical Analysis}

All of the experiments were conducted in triplicate, and statistical analyses were performed using the GraphPad Prism 5 software package (Graph Software, San Diego, CA, USA) [63]. One-way analysis of variance or two-way analysis of variance (ANOVA) was used to analyze the statistical significance of the differences between mean values for various vaccinated groups and the control group. Numerical data were expressed as means \pm standard deviation. The Kaplan-Meier method and log-rank test were used for the statistics and analysis of the survival curves. $p<0.05$ was considered a significant difference; $p<0.01$ was considered a standard significant difference; and $p<0.001$ was considered an extremely significant difference.

Supplementary Materials: Supplementary materials can be found at http://www.mdpi.com/1422-0067/ $17 / 3 / 416 /$ s1.

Acknowledgments: This study was supported by the National Natural Science Foundation of China $(31472179,31270981)$.

Author Contributions: Qing Liu and Qingke Kong conceived and designed the experiments. Qiong Liu, Xinxin Zhao, Jie Yi, Tian Liu and Kang Liang performed the experiments. Qing Liu, Qiong Liu and Qingke Kong analyzed the data. Qiong Liu and Qingke Kong wrote this manuscript.

Conflicts of Interest: The authors declare no conflict of interest.

\section{References}

1. Zhang, S.; Walters, N.; Cao, L.; Robison, A.; Yang, X.H. Recombinant salmonella vaccination technology and its application to human bacterial pathogens. Curr. Pharm. Biotechnol. 2013, 14, 209-219. [CrossRef] [PubMed] 
2. Rabsch, W.; Tschape, H.; Baumler, A.J. Non-typhoidal salmonellosis: Emerging problems. Microbes Infect. 2001, 3, 237-247. [CrossRef]

3. Hohmann, E.L. Nontyphoidal salmonellosis. Clin. Infect. Dis. 2001, 32, 263-269. [PubMed]

4. Majowicz, S.E.; Musto, J.; Scallan, E.; Angulo, F.J.; Kirk, M.; O’Brien, S.J.; Jones, T.F.; Fazil, A.; Hoekstra, R.M. The global burden of nontyphoidal salmonella gastroenteritis. Clin. Infect. Dis. 2010, 50, 882-889. [CrossRef] [PubMed]

5. Feasey, N.A.; Dougan, G.; Kingsley, R.A.; Heyderman, R.S.; Gordon, M.A. Invasive non-typhoidal salmonella disease: An emerging and neglected tropical disease in Africa. Lancet 2012, 379, 2489-2499. [CrossRef]

6. Morpeth, S.C.; Ramadhani, H.O.; Crump, J.A. Invasive non-typhi Salmonella disease in Africa. Clin. Infect. Dis. 2009, 49, 606-611. [CrossRef] [PubMed]

7. Reddy, E.A.; Shaw, A.V.; Crump, J.A. Community-acquired bloodstream infections in Africa: A systematic review and meta-analysis. Lancet Infect. Dis. 2010, 10, 417-432. [CrossRef]

8. Mastroeni, P.; Chabalgoity, J.A.; Dunstan, S.J.; Maskell, D.J.; Dougan, G. Salmonella: Immune responses and vaccines. Vet. J. 2001, 161, 132-164. [CrossRef] [PubMed]

9. Fraser, A.; Paul, M.; Goldberg, E.; Acosta, C.J.; Leibovici, L. Typhoid fever vaccines: Systematic review and meta-analysis of randomised controlled trials. Vaccine 2007, 25, 7848-7857. [CrossRef] [PubMed]

10. Ortiz, D.; Siegal, E.M.; Kramer, C.; Khandheria, B.K.; Brauer, E. Nontyphoidal cardiac salmonellosis: Two case reports and a review of the literature. Tex. Heart Inst. J. 2014, 41, 401-406. [CrossRef] [PubMed]

11. Singh, B. Salmonella vaccines for animals and birds and their future perspective. Open Vac. J. 2009, 2, 100-112. [CrossRef]

12. De Marchis, G.M.; Braunschweig, M.; Greuter, S. Nontyphoidal salmonellosis and mycotic aneurysm: A case report. Mt. Sinai J. Med. 2005, 72, 351-353. [PubMed]

13. Muhlradt, P.F.; Menzel, J. Outer membrane of salmonella-Sites of export of newly synthesized lipopolysaccharide on bacterial surface. Eur. J. Biochem. 1973, 35, 471-481. [CrossRef] [PubMed]

14. Osborn, M.J.; Gander, J.E.; Parisi, E.; Carson, J. Mechanism of assembly of the outer membrane of Salmonella typhimurium. Isolation and characterization of cytoplasmic and outer membrane. J. Biol. Chem. 1972, 247, 3962-3972. [PubMed]

15. Nikaido, H. Outer membrane of Salmonella typhimurium transmembrane diffusion of some hydrophobic substances. Biochim. Biophys. Acta 1976, 433, 118-132. [CrossRef]

16. Kuusi, N.; Nurminen, M.; Saxen, H.; Valtonen, M.; Makela, P.H. Immunization with major outer-membrane proteins in experimental salmonellosis of mice. Infect. Immun. 1979, 25, 857-862. [PubMed]

17. Schlecht, S.; Bhatnagar, N. Proteins from salmonella R-Mutants mediating protection against Salmonella typhimurium infection in mice. 2. Protection tests performed with proteins free from lipopolysaccharide. Zentralbl Bakteriol. Mikrobiol. Hyg. A 1985, 259, 367-377. [CrossRef]

18. Udhayakumar, V.; Muthukkaruppan, V.R. Protective immunity induced by outer-membrane proteins of Salmonella typhimurium in mice. Infect. Immun. 1987, 55, 816-821. [PubMed]

19. Isibasi, A.; Ortiz, V.; Vargas, M.; Paniagua, J.; Gonzalez, C.; Moreno, J.; Kumate, J. Protection against Salmonella typhi infection in mice after immunization with outer-membrane proteins isolated from Salmonella typhi 9,12,D,Vi. Infect. Immun. 1988, 56, 2953-2959. [PubMed]

20. Tabaraie, B.; Sharma, B.K.; Sharma, P.R.; Sehgal, R.; Ganguly, N.K. Evaluation of salmonella porins as a broad-spectrum vaccine candidate. Microbiol. Immunol. 1994, 38, 553-559. [CrossRef] [PubMed]

21. Wilson, G.; Fox, C.F. Biogenesis of microbial transport systems-Evidence for coupled incorporation of newly synthesized lipids and proteins into membrane. J. Mol. Biol. 1971, 55, 49-60. [CrossRef]

22. Machtiger, N.A.; Fox, C.F. Biochemistry of bacterial membranes. Annu. Rev. Biochem. 1973, 42, 575-600. [CrossRef] [PubMed]

23. Raetz, C.R.; Whitfield, C. Lipopolysaccharide endotoxins. Annu. Rev. Biochem. 2002, 71, 635-700. [CrossRef] [PubMed]

24. Whitfield, C.; Kaniuk, N.; Frirdich, E. Molecular insights into the assembly and diversity of the outer core oligosaccharide in lipopolysaccharides from Escherichia coli and Salmonella. J. Endotoxin Res. 2003, 9, 244-249. [CrossRef] [PubMed]

25. Frirdich, E.; Whitfield, C. Review: Lipopolysaccharide inner core oligosaccharide structure and outer membrane stability in human pathogens belonging to the Enterobacteriaceae. J. Endotoxin Res. 2005, 11, 133-144. [CrossRef] [PubMed] 
26. Kong, Q.; Yang, J.; Liu, Q.; Alamuri, P.; Roland, K.L.; Curtiss, R. Effect of deletion of genes involved in lipopolysaccharide core and $O$-antigen synthesis on virulence and immunogenicity of Salmonella enterica serovar Typhimurium. Infect. Immun. 2011, 79, 4227-4239. [CrossRef] [PubMed]

27. Ernst, R.K.; Guina, T.; Miller, S.I. Salmonella typhimurium outer membrane remodeling: Role in resistance to host innate immunity. Microbes Infect. 2001, 3, 1327-1334. [CrossRef]

28. Helander, I.M.; Latva-Kala, K.; Lounatmaa, K. Permeabilizing action of polyethyleneimine on Salmonella typhimurium involves disruption of the outer membrane and interactions with lipopolysaccharide. Microbiology 1998, 144, 385-390. [CrossRef] [PubMed]

29. Van Alphen, W.; Lugtenberg, B.; Berendsen, W. Heptose-deficient mutants of Escherichia coli K12 deficient in up to three major outer membrane proteins. Mol. Gen. Genet. MGG 1976, 147, 263-269. [CrossRef] [PubMed]

30. Ried, G.; Hindennach, I.; Henning, U. Role of lipopolysaccharide in assembly of Escherichia coli outer membrane proteins OmpA, OmpC, and OmpF. J. Bacteriol. 1990, 172, 6048-6053. [PubMed]

31. Rivera, M.; Bertasso, A.; McCaffrey, C.; Georgopapadakou, N.H. Porins and lipopolysaccharide of Escherichia coli ATCC 25922 and isogenic rough mutants. FEMS Microbiol. Lett. 1993, 108, 183-187. [CrossRef] [PubMed]

32. Singh, S.P.; Williams, Y.U.; Miller, S.; Nikaido, H. The c-terminal domain of Salmonella enterica serovar Typhimurium OmpA is an immunodominant antigen in mice but appears to be only partially exposed on the bacterial cell surface. Infect. Immun. 2003, 71, 3937-3946. [CrossRef] [PubMed]

33. Singh, S.P.; Singh, S.R.; Williams, Y.U.; Jones, L.; Abdullah, T. Antigenic determinants of the OmpC porin from Salmonella typhimurium. Infect. Immun. 1995, 63, 4600-4605. [PubMed]

34. Gaffga, N.H.; Barton Behravesh, C.; Ettestad, P.J.; Smelser, C.B.; Rhorer, A.R.; Cronquist, A.B.; Comstock, N.A.; Bidol, S.A.; Patel, N.J.; Gerner-Smidt, P.; et al. Outbreak of salmonellosis linked to live poultry from a mail-order hatchery. N. Engl. J. Med. 2012, 366, 2065-2073. [CrossRef] [PubMed]

35. Havelaar, A.H.; Ivarsson, S.; Lofdahl, M.; Nauta, M.J. Estimating the true incidence of campylobacteriosis and salmonellosis in the European Union, 2009. Epidemiol. Infect. 2013, 141, 293-302. [CrossRef] [PubMed]

36. Hoelzer, K.; Switt, A.I.M.; Wiedmann, M. Animal contact as a source of human non-typhoidal salmonellosis. Vet. Res. 2011, 42. [CrossRef] [PubMed]

37. Carlone, G.M.; Thomas, M.L.; Rumschlag, H.S.; Sottnek, F.O. Rapid microprocedure for isolating detergent-insoluble outer-membrane proteins from Haemophilus species. J. Clin. Microbiol. 1986, 24, 330-332. [PubMed]

38. Ruiz, A.; Oliveira, S.; Torremorell, M.; Pijoan, C. Outer membrane proteins and DNA profiles in strains of Haemophilus parasuis recovered from systemic and respiratory sites. J. Clin. Microbiol. 2001, 39, 1757-1762. [CrossRef] [PubMed]

39. Fedorka-Cray, P.J.; Huether, M.J.; Stine, D.L.; Anderson, G.A. Efficacy of a cell extract from Actinobacillus (Haemophilus) pleuropneumoniae serotype 1 against disease in swine. Infect. Immun. 1990, 58, 358-365. [PubMed]

40. Łaniewski, P.; Mitra, A.; Karaca, K.; Khan, A.; Prasad, R.; Curtiss, R.; Roland, K.L. Evaluation of protective efficacy of live attenuated Salmonella enterica serovar Gallinarum vaccine strains against fowl typhoid in chickens. Clin. Vaccine Immunol. 2014, 21, 1267-1276. [CrossRef] [PubMed]

41. Schmidtke, J.R.; Dixon, F.J. Immune response to a hapten coupled to a nonimmunogenic carrier. Influence of lipopolysaccharide. J. Exp. Med. 1972, 136, 392-397. [CrossRef] [PubMed]

42. Uchiyama, T.; Jacobs, D.M. Modulation of immune response by bacterial lipopolysaccharide (LPS): Cellular basis of stimulatory and inhibitory effects of LPS on the in vitro IgM antibody response to a T-dependent antigen. J. Immunol. 1978, 121, 2347-2351. [PubMed]

43. Santos, R.L.; Zhang, S.; Tsolis, R.M.; Kingsley, R.A.; Adams, L.G.; Baumler, A.J. Animal models of Salmonella infections: Enteritis versus typhoid fever. Microbes Infect. 2001, 3, 1335-1344. [CrossRef]

44. Humphrey, T.J.; Williams, A.; McAlpine, K.; Lever, M.S.; Guard-Petter, J.; Cox, J.M. Isolates of Salmonella enterica Enteritidis PT4 with enhanced heat and acid tolerance are more virulent in mice and more invasive in chickens. Epidemiol. Infect. 1996, 117, 79-88. [CrossRef] [PubMed]

45. Carter, P.B.; Collins, F.M. The route of enteric infection in normal mice. J. Exp. Med. 1974, 139, 1189-1203. [CrossRef] [PubMed]

46. Emoto, M.; Danbara, H.; Yoshikai, Y. Induction of $\gamma / \delta \mathrm{T}$ cells in murine salmonellosis by an avirulent but not by a virulent strain of Salmonella choleraesuis. J. Exp. Med. 1992, 176, 363-372. [CrossRef] [PubMed] 
47. Ishigami, M.; Nishimura, H.; Naiki, Y.; Yoshioka, K.; Kawano, T.; Tanaka, Y.; Taniguchi, M.; Kakumu, S.; Yoshikai, Y. The roles of intrahepatic Valpha14 ${ }^{+} \mathrm{NK} 1.1^{+} \mathrm{T}$ cells for liver injury induced by Salmonella infection in mice. Hepatology 1999, 29, 1799-1808. [CrossRef] [PubMed]

48. Greisman, S.; Johnston, C. Review: Evidence against the hypothesis that antibodies to the inner core of lipopolysaccharides in antisera raised by immunization with enterobacterial deep-rough mutants confer broad-spectrum protection during Gram-negative bacterial sepsis. J. Endotoxin Res. 1997, 4, 123-153. [CrossRef]

49. Beltran, P.; Musser, J.M.; Helmuth, R.; Farmer, J.J.; Frerichs, W.M.; Wachsmuth, I.K.; Ferris, K.; McWhorter, A.C.; Wells, J.G.; Cravioto, A. Toward a population genetic analysis of Salmonella: Genetic diversity and relationships among strains of serotypes S. choleraesuis, S. derby, S. dublin, S. enteritidis, S. heidelberg, S. infantis, S. newport, and S. typhimurium. Proc. Natl. Acad. Sci. USA 1988, 85, 7753-7757. [CrossRef] [PubMed]

50. Thomson, N.R.; Clayton, D.J.; Windhorst, D.; Vernikos, G.; Davidson, S.; Churcher, C.; Quail, M.A.; Stevens, M.; Jones, M.A.; Watson, M. Comparative genome analysis of Salmonella Enteritidis PT4 and Salmonella Gallinarum 287/91 provides insights into evolutionary and host adaptation pathways. Genome Res. 2008, 18, 1624-1637. [CrossRef] [PubMed]

51. Masoud, H. LPS-based conjugate vaccines composed of saccharide antigens of smooth-type Salmonella enteritidis and rough-type S. gallinarum 9R bound to bovine serum albumin. Scand. J. Infect. Dis. 2007, 39, 315-322. [CrossRef] [PubMed]

52. Johns, M.; Skehill, A.; McCabe, W.R. Immunization with rough mutants of Salmonella minnesota. IV. Protection by antisera to $\mathrm{O}$ and rough antigens against endotoxin. J. Infect. Dis. 1983, 147, 57-67. [CrossRef] [PubMed]

53. Siber, G.R.; Kania, S.A.; Warren, H.S. Cross-reactivity of rabbit antibodies to lipopolysaccharides of Escherichia coli J5 and other gram-negative bacteria. J. Infect. Dis. 1985, 152, 954-964. [CrossRef] [PubMed]

54. Gigliotti, F.; Shenep, J.L. Failure of monoclonal antibodies to core glycolipid to bind intact smooth strains of Escherichia coli. J. Infect. Dis. 1985, 151, 1005-1011. [CrossRef] [PubMed]

55. Troncoso, G.; Sanchez, S.; Kolberg, J.; Rosenqvist, E.; Veiga, M.; Ferreiros, C.M.; Criado, M. Analysis of the expression of the putatively virulence-associated neisserial protein RmpM (class 4) in commensal Neisseria and Moraxella catarrhalis strains. FEMS Microbiol. Lett. 2001, 199, 171-176. [CrossRef] [PubMed]

56. Nakayama, K.; Kelly, S.M.; Curtiss, R. Construction of an Asd+ expression-cloning vector: Stable maintenance and high level expression of cloned genes in a Salmonella vaccine strain. Nat. Biotechnol. 1988, 6, 693-697. [CrossRef]

57. Roland, K.; Curtiss, R., III; Sizemore, D. Construction and evaluation of a $\Delta c y a \Delta c r p$ Salmonella typhimurium strain expressing avian pathogenic Escherichia coli O78 LPS as a vaccine to prevent airsacculitis in chickens. Avian Dis. 1999, 43, 429-441. [CrossRef] [PubMed]

58. Shubeita, H.E.; Sambrook, J.F.; McCormick, A.M. Molecular cloning and analysis of functional cDNA and genomic clones encoding bovine cellular retinoic acid-binding protein. Proc. Natl. Acad. Sci. USA 1987, 84, 5645-5649. [CrossRef] [PubMed]

59. Li, Y.H.; Wang, S.F.; Xin, W.; Scarpellini, G.; Shi, Z.X.; Gunn, B.; Roland, K.L.; Curtiss, R. A sopB Deletion mutation enhances the immunogenicity and protective efficacy of a heterologous antigen delivered by live attenuated Salmonella enterica vaccines. Infect. Immun. 2008, 76, 5238-5246. [CrossRef] [PubMed]

60. Hitchcock, P.J.; Brown, T.M. Morphological heterogeneity among Salmonella lipopolysaccharide chemotypes in silver-stained polyacrylamide gels. J. Bacteriol. 1983, 154, 269-277. [PubMed]

61. Bjerre, A.; Brusletto, B.; Mollnes, T.E.; Fritzsonn, E.; Rosenqvist, E.; Wedege, E.; Namork, E.; Kierulf, P.; Brandtzaeg, P. Complement activation induced by purified Neisseria meningitidis lipopolysaccharide (LPS), outer membrane vesicles, whole bacteria, and an LPS-free mutant. J. Infect. Dis. 2002, 185, 220-228. [CrossRef] [PubMed]

62. Cloeckaert, A.; Kerkhofs, P.; Limet, J.N. Antibody response to Brucella outer membrane proteins in bovine brucellosis: Immunoblot analysis and competitive enzyme-linked immunosorbent assay using monoclonal antibodies. J. Clin. Microbiol. 1992, 30, 3168-3174. [PubMed]

63. Motulsky, H. Prism 5 statistics guide, 2007; GraphPad Software: La Jolla, CA, USA, 2007; pp. 1-26.

(C) 2016 by the authors; licensee MDPI, Basel, Switzerland. This article is an open access article distributed under the terms and conditions of the Creative Commons by Attribution (CC-BY) license (http://creativecommons.org/licenses/by/4.0/). 